\title{
Lithium Melonate, Li3[C6N7(NCN)3].6H20 - Synthesis, Crystal Structure and Thermal Properties of a Novel Precursor for Graphitic Carbon Nitrides
}

\begin{tabular}{|r|l|}
\hline Journal: & Zeitschrift für Anorganische und Allgemeine Chemie \\
\hline Manuscript ID: & zaac.200900326.R1 \\
\hline Date Submitted by the \\
Author: & Article \\
\hline Complete List of Authors: & $\begin{array}{l}\text { Kroke, Edwin; TU Bergakademie Freiberg, Institut fuer } \\
\text { Anorganische Chemie } \\
\text { Clauss, Corinna; TU Bergakademie Freiberg, Institut fuer } \\
\text { Anorganische Chemie } \\
\text { Wagler, Jörg; TU Bergakademie Freiberg, Institut fuer Anorganische } \\
\text { Chemie } \\
\text { Schwarz, Marcus; TU Bergakademie Freiberg, Institut fuer } \\
\text { Anorganische Chemie } \\
\text { Schwarzer, Anke; TU Bergakademie Freiberg, Institut fuer } \\
\text { Anorganische Chemie }\end{array}$ \\
\hline Keywords: & \begin{tabular}{l} 
s-Heptazine, Tri-s-triazine, Crystal Structure, Carbon Nitride \\
\hline
\end{tabular} \\
\hline
\end{tabular}

\section{s scholaroNE" \\ Manuscript Central}


Abstract. A new $s$-heptazine derivative, lithium melonate $\mathrm{Li}_{3}\left[\mathrm{C}_{6} \mathrm{~N}_{7}(\mathrm{NCN})_{3}\right]$ (2), has been prepared from potassium melonate using an ion exchanger resin. The crystal structure of the hexahydrate $\mathrm{Li}_{3}\left[\mathrm{C}_{6} \mathrm{~N}_{7}(\mathrm{NCN})_{3}\right] \cdot 6 \mathrm{H}_{2} \mathrm{O}, 2 \mathbf{a}$ has been determined by X-ray diffraction analysis (hexagonal, $P 6_{3} / m, a=b=$ 12.2263(6), c = 6.8854(6) $\AA, V=891.35(10) \AA^{3}$ ). The results show that this s-heptazine derivative adopts ideal $C_{3 h}$ symmetry, thus comprising $1 / 6$ of the formula moiety in the asymmetric unit. ${ }^{13} \mathrm{C}$ NMR data indicate that no melonate-lithium interaction occurs in solution, while $\mathrm{Li}$ is tetrahedrally coordinated by two $\mathrm{O}$ - and two $\mathrm{N}$-atoms in $\mathbf{2 a}$ in the solid. The title

\section{Introduction}

Graphitic as well as diamond-like carbon nitrides are interesting materials due to various intriguing chemical and physical properties [1]. One sub-class of the first group of these materials are $s$ hepatzine-based carbon(IV) nitrides containing an alternating arrangement of $\mathrm{C}$ - and $\mathrm{N}$-atoms. One of these graphite-like structures, namely $\left[\mathrm{C}_{6} \mathrm{~N}_{7}(\mathrm{~N})\right]_{\mathrm{n}}$, in which the $s$-heptazine units are linked via $\mathrm{sp}^{2}$-hybridised $\mathrm{N}$-atoms, has been calculated to be the most stable carbon(IV) nitride [2]. An alternative architecture for a graphite-like carbon(IV) nitride is provided by linking the completely planar and thermally very stable $\mathrm{C}_{6} \mathrm{~N}_{7}$ motif via $\mathrm{NCN}$ units, i.e. cyanamide or carbodiimide groups. The so-called melonate anion $\left[\mathrm{C}_{6} \mathrm{~N}_{7}(\mathrm{NCN})_{3}\right]^{3-}$ represents a very promising starting point for the preparation of such carbon nitride derivatives.

First reports on melonates date back to the 1830s when Gmelin first synthesized potassium melonate $\mathrm{K}_{3}\left[\mathrm{C}_{6} \mathrm{~N}_{7}(\mathrm{NCN})_{3}\right]$ (1) [3]. Only a few years later, Liebig obtained the same compound by dissolving the polymer melon in a potassium thiocyanate melt [4]. Although Pauling et al. discussed the melonate structure in the 1930s [5], a comprehensive structural analysis of a melonate was not available until we reported the first single crystal structure of a melonate, namely the hydrate $1\left(\mathrm{~K}_{3}\left[\mathrm{C}_{6} \mathrm{~N}_{7}(\mathrm{NCN})_{3}\right] \cdot 5 \mathrm{H}_{2} \mathrm{O}\right)$ in 2005 [6]. In the past few years compounds based on the $s$-heptazine unit have attracted considerable attention. These and related derivatives can be used e.g. as active metal-free catalyst for Friedel-Crafts reactions [7],

\footnotetext{
* Prof. Dr. Edwin Kroke

Institut für Anorganische Chemie

Technische Universität Bergakademie Freiberg

Leipziger Straße 29

D-09596 Freiberg, Germany

Fax: +49-(0)3731-39-4058

E-mail: edwin.kroke@chemie.tu-freiberg.de
}

compound 2 was further characterized by FTIR, Raman spectroscopy, TG/DTA and elemental analysis. In spite of the high nitrogen content 2 proved to be thermally stable up to $\sim 500^{\circ} \mathrm{C}$. The latter observation is typical for melonates and has been reported other s-heptazin derivatives as well.

Keywords: $s$-Heptazine; Tri-s-triazine; Crystal Structure; Heterocycles; Carbon Nitride

formation of organic-inorganic hybrid gels [8], as graphitic carbon nitride precursors [9], potential flame retardants [10] or for photocatalysis [11]. Hence, various attempts were dedicated to the syntheses of new carbon nitride precursors. Whereas Schnick et al. have very recently put effort of the syntheses and crystal structure determination of the melonates of calcium (namely the protonated hydrate $\mathrm{Ca}\left[\mathrm{HC}_{6} \mathrm{~N}_{7}(\mathrm{NCN})_{3}\right] \cdot 7 \mathrm{H}_{2} \mathrm{O}$ [12]) and rubidium and caesium (namely $\mathrm{Rb}_{3}\left[\mathrm{C}_{6} \mathrm{~N}_{7}(\mathrm{NCN})_{3}\right] \cdot 3 \mathrm{H}_{2} \mathrm{O}$ and $\mathrm{Cs}_{3}\left[\mathrm{C}_{6} \mathrm{~N}_{7}(\mathrm{NCN})_{3}\right] \cdot 3 \mathrm{H}_{2} \mathrm{O}$ [13]), we report on the synthesis, single crystal structure and selected properties of lithium melonate.

\section{Results and Discussion}

\section{Synthesis}

As the alkali melonates proved soluble in water and aqueous solutions of mineral acids, an acidic macroreticular exchange resin offers a general approach to the synthesis of melonates with any counterion that can be loaded onto the resin. As demonstrated here, this route proved suitable for the synthesis of lithium melonate, potassium melonate serving as starting material. The ion exchange resin was treated with a solution of hydrochlorid acid, followed by loading of the resin with lithium ions, which was done with an aqueous lithium hydroxide solution. The Li-vs.-K ion exchange itself was then carried out with an aqueous solution of both $\mathrm{K}_{3}\left[\mathrm{C}_{6} \mathrm{~N}_{7}(\mathrm{NCN})_{3}\right]$ and lithium hydroxide (note: the additive lithium hydroxide is necessary to keep the mixture basic). The crude lithium melonate solution was collected and its volume was diminished by evaporation of water to yield the raw product which needs to be cleaned from lithium chloride via washing with THF and finally to be recrystallized from distilled water to obtain the hexahydrate $\mathbf{2 a}$. 


\section{Crystal Structure}

The asymmetric unit of 2a (Figure 1) comprises 1/6 lithium melonate $\mathrm{Li}_{3}\left[\mathrm{C}_{6} \mathrm{~N}_{7}(\mathrm{NCN})_{3}\right]$ and one water molecule. In addition to the threefold symmetry (e.g., threefold axes through N1 orthogonal to the heptazine plane), all atoms except the Li-bound water molecules are situated on a crystallographically imposed bisecting plane.

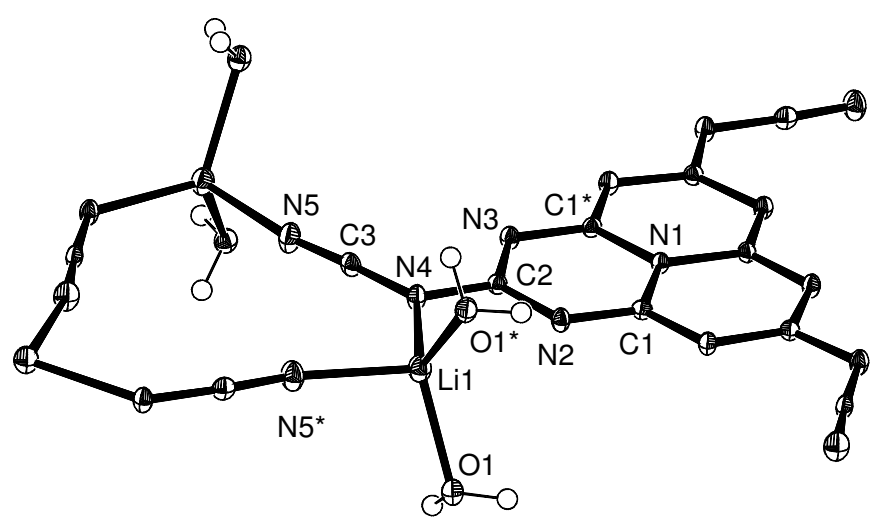

Figure 1. Section of the crystal structure of 2a (ORTEP diagram with ellipsoids at the $50 \%$ probability level, non- $\mathrm{H}$ atoms of the asymmetric unit labeled, selected symmetry equivalent atoms asterisked). Bond lengths $[\AA]$ and angles [deg.]: C1-N1 1.400(1), C1-N2 1.318(2), C2-N2 1.352(2), C2-N3 1.362(2), C2-N4 1.342(2), C1*-N3 1.332(2), C3-N4 1.319(2), C3-N5 1.157(2), Li1-O1 1.964(2), Li1-N4 2.042(3), Li1-N5* 1.997(3); O1-Li1-O1* 114.2(1), N4-Li1-N5* 100.4(1), O1-Li1-N4 117.0(1), O1-Li1-N5* 102.1(1), N4-C3-N5 176.1(2), C2-N4-C3 117.6(1), C2-N4-Li1 111.1(1).

The coordination sphere about the Li-ion can be considered distorted tetrahedral with angles ranging between 100 and $117^{\circ}$. In addition to two water molecules bound to each lithium ion the Licoordination sphere is furnished by two different kinds of $\mathrm{N}$-donor sites. These are the $\mathrm{sp}^{2}$-type lone pair of atom $\mathrm{N} 4$ coordinating Li1 to accomplish a roughly trigonal environment around N4 and the lone pair of $\mathrm{N} 5$ coordinating in a nitrile fashion, thus providing for an almost linear arrangement N4-C3-N5-Li1*. The nitrile (or cyan) character of the C3-N5 moiety is furthermore reflected in the significantly shorter bond of C3 to nitrogen atom N5 (1.157(2) A), representing a noticeably shortened double bond, whereas the distance of 1.319(2) $\AA$ between $\mathrm{C} 3$ and N4 is characteristic of weakened $\mathrm{C}=\mathrm{N}$ bonds. Within the heptazine core the $\mathrm{C}-\mathrm{N}$ bonds are in the typical range as encountered with other cyameluric derivatives $[2,6,9,12-14]$, i.e., the $\mathrm{C}-\mathrm{N}$ bond to the central nitrogen atom $\mathrm{N} 1$ being notably longer than the surrounding $\mathrm{C}=\mathrm{N}$ bonds, the features of which are almost midway between single- and doublebonds due to the conjugated $\pi$-system. The bond length C2-N4 (1.342(2) §̊) perfectly falls in this range, thus demonstrating the influence of $\pi$-conjugation involving both the heptazine core and its cyanamide substituents. Thus, it appears plausible that, in addition to $\mathbf{2 a}$, further related systems (i.e., melonates of potassium [6] and rubidium [13] as well as cyameluric azide $\left(\mathrm{C}_{6} \mathrm{~N}_{7}\right)\left(\mathrm{N}_{3}\right)_{3}$ [15] with the $\mathrm{N}_{3}$-moiety resembling an isoelectronic substitute for the cyanamide group of the melonates) exhibit coplanar arrangement of the heptazine system and its substituents in the solid state. This coplanarity supports the overall crystal packing of $\mathbf{2 a}$.

The crystal structure of $\mathbf{2 a}$ can be regarded as a layer structure created by a 2D network of alternating heptazine cores and $(-\mathrm{NCN}-\mathrm{Li}-)_{3}$ ring systems with an inter-layer separation of half the crystallographic $c$-axis (i.e., $3.44 \AA$ ). Although indicating a graphitic inter-layer distance, the heptazine moieties are not stacked on top of each other. Instead, a (-NCN-Li- $)_{3}$ macrocycle is located on top of each heptazine, sharing the threefold axis through $\mathrm{N} 1$ and the centroid of the (-NCN-Li-) $)_{3}$ system (Figure 2).

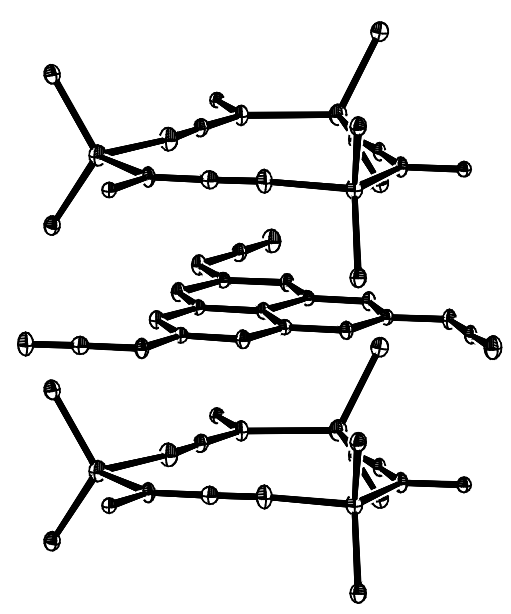

Figure 2. ORTEP representation of the parallel stacking of heptazine cores and $\left[-\mathrm{NCN}-\mathrm{Li}\left(\mathrm{OH}_{2}\right)_{2}-\right)_{3}$ macrocycles in the structure of $\mathbf{2 a}$.

Thus, the inter-heptazine separations equal the crystallographic $c$-axis, i.e., $6.885 \AA$, not providing for any direct attractive forces (in sharp contrast to the structure of potassium melonate [6] and the melonates of $\mathrm{Rb}$ and $\mathrm{Cs}$ [13]). The attractive forces between the layers in the structure of $\mathbf{2 a}$ are dominated by two kinds of hydrogen bridges, i.e. (i) circular $(\mathrm{O}-\mathrm{H} . . \mathrm{O}-\mathrm{H} \ldots)_{3}$ arrangements midway between the layers and (ii) $\mathrm{O}-\mathrm{H}$... N contacts involving atom N3 and its symmetry equivalents (Figure 3 ).

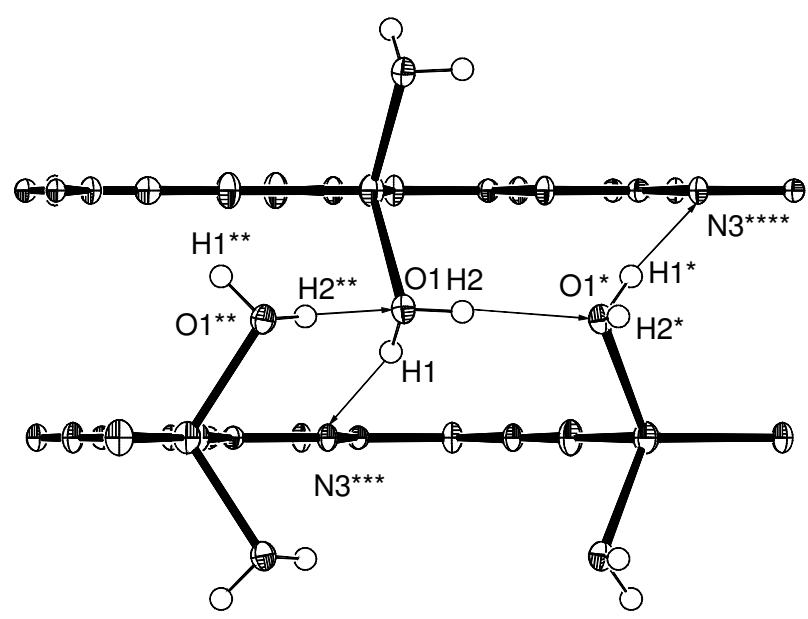

Figure 3. Section of the crystal structure of 2a with thin arrows indicating intermolecular hydrogen bridges. Interatomic distances $[\AA]$ : O1-H1 0.85(2), O1-H2 $0.85(2), \mathrm{H} 2-\mathrm{O} 1 * 2.00(2), \mathrm{H} 1-\mathrm{N} 3 * * * 2.18(2)$.

\section{Spectroscopic properties}

The FTIR spectra (Figure 4) of the lithium melonate dried at $200^{\circ} \mathrm{C} \mathbf{2 b}$, which contains about one water molecule per lithium ion (see below), shows the typical bending and stretching vibrations of the $s$-heptazine ring at 805 and $1196-1641 \mathrm{~cm}^{-1}$ representing the high symmetry of the molecular structure. At $2157 \mathrm{~cm}^{-1}$ a sharp signal characteristic of the $\mathrm{C} \equiv \mathrm{N}$ valence vibration emerges, while 
the water molecules are represented by the (broad) $\mathrm{OH}$ vibrations at $3390 \mathrm{~cm}^{-1}$. Though the N...H distance of $2.177 \AA$ in the crystal might serve as a source for a hydrogen-bridge N...H vibration no clear corresponding signal in the region $2600-3600 \mathrm{~cm}^{-1}$ was observed. Nevertheless, all observed signals point to the presence of the lithium melonate.

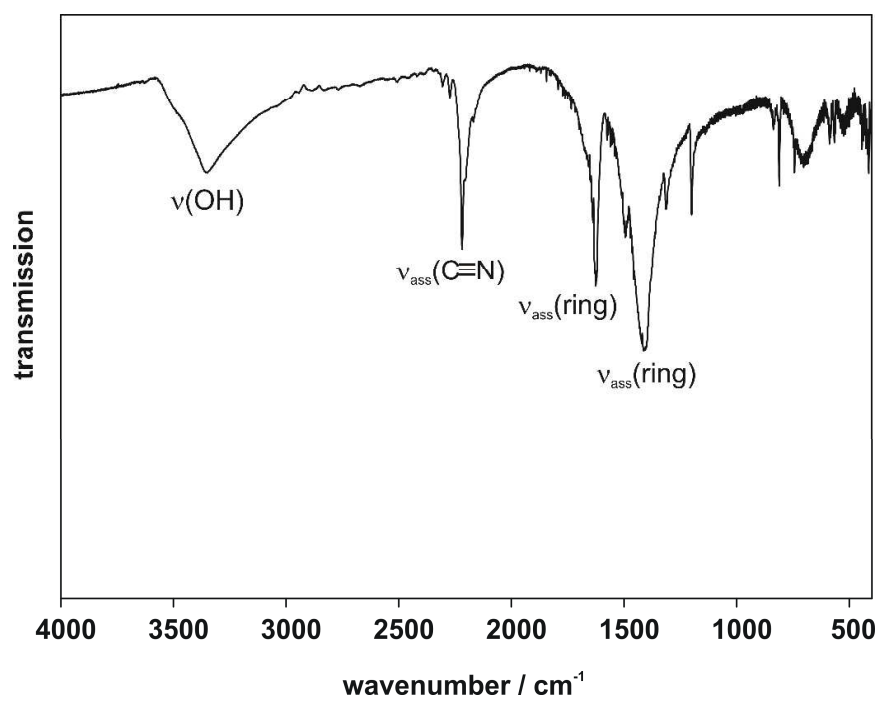

Figure 4. FTIR spectrum of $\mathrm{Li}_{3}\left[\mathrm{C}_{6} \mathrm{~N}_{7}(\mathrm{NCN})_{3}\right] \cdot 1 \mathrm{H}_{2} \mathrm{O}$ (2b).

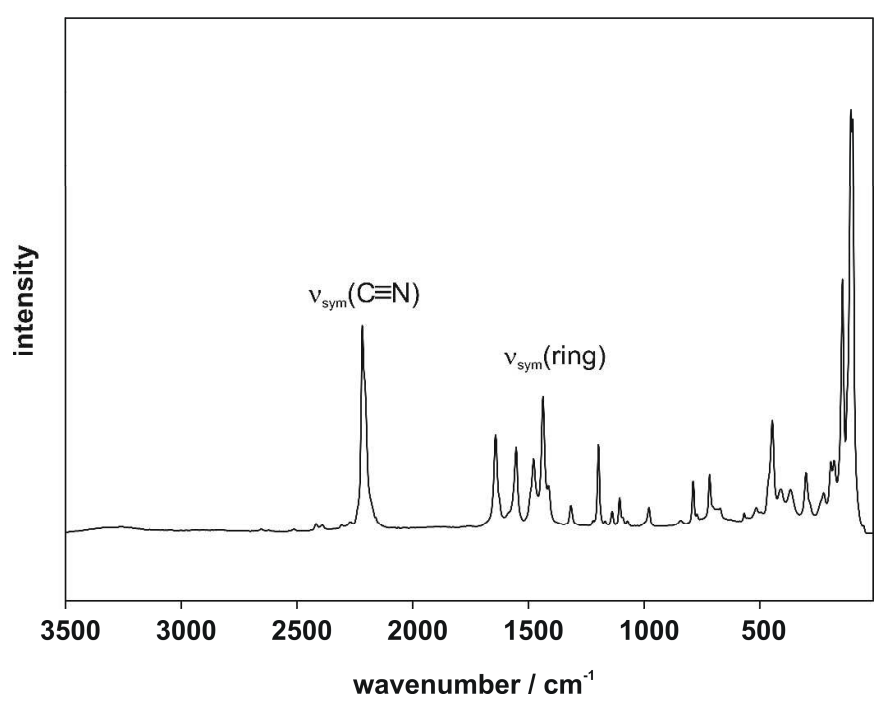

Figure 5. Raman spectrum of $\mathrm{Li}_{3}\left[\mathrm{C}_{6} \mathrm{~N}_{7}(\mathrm{NCN})_{3}\right] \cdot 1 \mathrm{H}_{2} \mathrm{O}(\mathbf{2 b})$.

The Raman spectrum depicted in Figure 5 shows the typical symmetric vibrations of the $\mathrm{CN}$ group and the $s$-heptazine ring of the $\mathrm{C}_{6} \mathrm{~N}_{7}(\mathrm{NCN})_{3}$-unit.

${ }^{13} \mathrm{C}$ NMR data recorded from an aqueous solution of the title compound proved the presence of the melonate ion with the typical signals at 174.3 and $158.6 \mathrm{ppm}$ for the outer and the inner heptazine carbon atoms, respectively, and a peak at $124.9 \mathrm{ppm}$ representing the cyanamide $\mathrm{C}$-atoms. These chemical shift values are completely identical to the data reported for potassium melonate [6], indicating that no significant cation-anion interaction is present in aqueous solution at room temperature. In contrast, the solid state ${ }^{13} \mathrm{C}$ NMR data are slightly shifted (see Exp. Part) supporting the $\mathrm{Li}^{+}$-melonate coordination found in the single crystal structure analysis discussed above.

\section{Thermal Properties}

Figure 3 shows the TG and DTA curves of $\mathbf{2 a}$ recorded in the temperature range from 25 to $800{ }^{\circ} \mathrm{C}$. The lithium melonate dehydrates at $164{ }^{\circ} \mathrm{C}$ (DTA), indicated by a mass loss of $22 \%$ in the range between 115 and $210{ }^{\circ} \mathrm{C}$. This mass loss corresponds to the liberation of five water molecules. The sixth water molecule appears to remain in the molecular packing even at higher temperatures, leading to a slight mass loss over the range up to $500{ }^{\circ} \mathrm{C}$ before further thermal decomposition commences. This high thermal stability is typical for melonates $[6,12,13]$ and has been found the related cyamelurates as well [16].

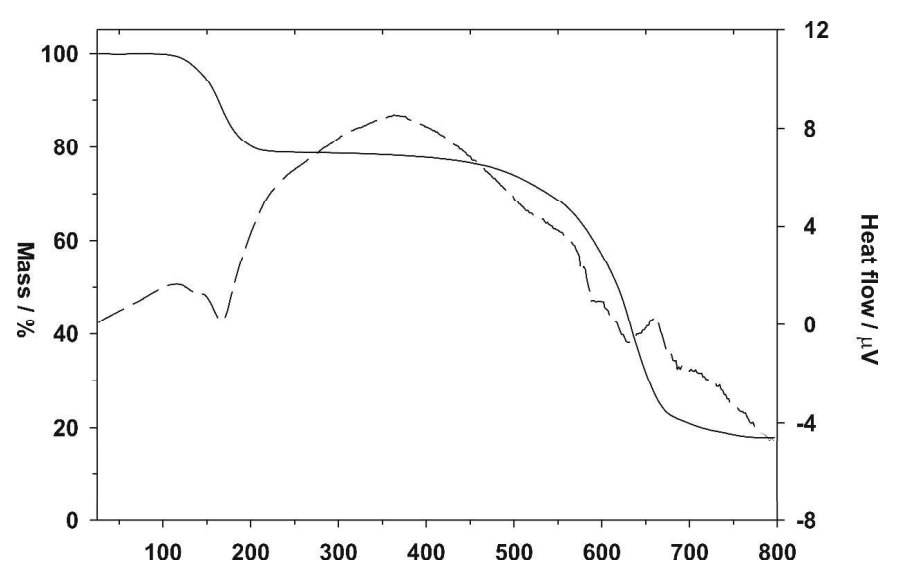

Figure 6. TG and DTA curves of $\mathrm{Li}_{3}\left[\mathrm{C}_{6} \mathrm{~N}_{7}(\mathrm{NCN})\right] \cdot 5 \mathrm{H}_{2} \mathrm{O}$, recorded with a heating of $5 \mathrm{~K} / \mathrm{min}$.

\section{Conclusions}

Here we presented the synthesis of lithium melonate, its spectroscopic characterisation and the single crystal structure of the hexahydrate. As was expected from the data known for corresponding potassium salt, the anion is completely planar in the solid state with conjugation within the $\mathrm{C}_{6} \mathrm{~N}_{7}$-core and the exocyclic $\mathrm{N}$-atoms. The NCN-units are coplanar with the $\mathrm{C}_{6} \mathrm{~N}_{7}$-tricycle, but are better described as cyanamide than carbodiimide groups. Interestingly, the $\mathrm{Li}$ ions are located exactly in the same plane being coordinated to both of the $\mathrm{N}$-atoms of these NCN-units and to two water molecules in a nearly tetrahedral mode. Due to the fact that lithium chloride is better soluable in organic solvents such as THF than the other alkali chlorides, the title compound is considered to be the most promising precursor for reactions with selected element chlorides to form extended (insoluable) carbon nitride networks. Some of such networks are potentially hydrolytically sensitive, and in this case the side product $(\mathrm{LiCl})$ has to be removed via extraction with an anhydrous solvent (e.g. THF). However, the title compound 2 itself is hydrolytically (e.g. against strong acids) and thermally very stable, similar to other melonates and s-hepatzine derivates.

\section{Experimental Section}

\section{Starting materials}

All chemicals were used in p.a. quality as obtained from the suppliers. Melon was obtained in crude form from Durferrit $\mathrm{GmbH}$ (Hanau, Germany) and 
purified either by annealing at $500^{\circ} \mathrm{C}$ and/or extraction of impurities with water. The identity and purity of this starting materials was checked using elemental analyses, FTIR-spectroscopy and thorough solid state ${ }^{13} \mathrm{C}$ - and ${ }^{15} \mathrm{~N}$-NMR studies.

\section{Synthesis}

1: Potassium melonate was synthesized according to an optimized literature synthesis [6]. Melon powder $(20 \mathrm{~g}, 99.5 \mathrm{mmol})$ and $\mathrm{KSCN}(40 \mathrm{~g}, 137.5$ mmol) were mixed and heated carefully to $400{ }^{\circ} \mathrm{C}$ for 60 minutes, then to about $450-500{ }^{\circ} \mathrm{C}$ for additional 30 minutes. The hot reaction mixture was filtered and slowly cooled to room temperature. The raw melonate was dissolved in distilled water and separated, recrystallized twice from acetonewater and once from water. Final washing with $\mathrm{EtOH}$ and drying at $80^{\circ} \mathrm{C}$ in drying oven yields the pentahydrate of potassium melonate.

2: Lithium melonate was synthesized using a strong acidic ion exchanger resin (AMBERLITE IR120) in a glass column. A glass column equipped with a fritted glass sinter bottom (porosity grade 4 ) was loaded with the exchanger resin. After cleaning $50 \mathrm{ml}$ of the resin with $\mathrm{HCl} /$ water $(50 \mathrm{~mL} / 50$ $\mathrm{mL}$ ) and distilled water, the resin was loaded with lithium via flushing 100 $\mathrm{mL}$ of a $2.5 \mathrm{M} \mathrm{LiOH}$-solution through the column. The ion exchange itself was performed with a solution of $1.24 \mathrm{~g}(2.53 \mathrm{mmol})$ potassium melonate pentahydrate and $0.599 \mathrm{~g}(25.0 \mathrm{mmol})$ lithium hydroxide in $50 \mathrm{~mL}$ distilled water. The resulting solution of lithium melonate collected from this column was neutralized with hydrochlorid acid and the water was evaporated. The separated solid was washed with THF to remove the lithium chloride. Final recrystallization from water and drying in vacuum at $200{ }^{\circ} \mathrm{C}$ for $24 \mathrm{~h}$ yields lithium melonate monohydrate $\mathbf{2 b}$ as a white solid. Yield: $83 \mathrm{mg}(\sim 10 \%)$. The hexahydrate 2a was obtained via recrystallisation from distilled water Various samples were analysed by combustion chemical analysis. Although the materials appeared pure based on the solution NMR data and EDXanalyses concerning potassium and/or chloride residues, determined elemental compositions did not fit to the calculated ones. This is probably due to an incomplete combustion of the heptazine unit in certain cases. Nevertheless, the "best" analysis was obtained for a sample dried at $80^{\circ} \mathrm{C}$ indicating that at least the $\mathrm{C}: \mathrm{N}$-ratio corresponds to the calculated ratio. Anal calc. for $\mathrm{Li}_{3} \mathrm{C}_{6} \mathrm{~N}_{7}(\mathrm{NCN})_{3} \cdot 5 \mathrm{H}_{2} \mathrm{O}$ (419.1): C 26.95, $\mathrm{H} 0.78, \mathrm{~N} 45.40$; found $\mathrm{C}$ 28.86, H 1.73, N 49.05\%; C/N ratio: calcd. 0.59 , found 0.59. REM: EDX analysis has shown no potassium and no chloride. ${ }^{13} \mathrm{C}$ NMR $\left(101 \mathrm{MHz}, \mathrm{D}_{2} \mathrm{O}\right)$ $\delta=174.3\left(C\left(\mathrm{NLiCN}_{2} \mathrm{~N}_{2}\right), 158.6\left(C \mathrm{~N}_{3}\right), 124.89 \mathrm{ppm}(C \equiv \mathrm{N})\right.$. IR $(\mathrm{KBr}): 3390$, $2157,1641,1428,1292,1196,805 .{ }^{13} \mathrm{C}$ CP/MAS NMR (101 MHz) $\delta=$ $172.2\left(C\left(\mathrm{NLiCN}^{2} \mathrm{~N}_{2}\right), 155.6\left(C_{3}\right), 120.33 \mathrm{ppm}(C \equiv \mathrm{N})\right.$.

\section{X-Ray Structure Determination}

X-ray diffraction data of the hexahydrate 2a were recorded on a BRUKERNONIUS-X8 APEXII-CCD-diffractometer with Mo- $\mathrm{K}_{\alpha}$-radiation. The structure was solved with direct methods [17] and refined with full-matrix least-squares methods against $F^{2}$ using SHELXL-97 [18]. All non-hydrogen atoms were refined anisotropically. Hydrogen atoms of the water molecules were located from residual electron density and refined isotropically without bond length restraints.

Crystal structure of $2 \mathbf{a}: \mathrm{C}_{9} \mathrm{H}_{12} \mathrm{Li}_{3} \mathrm{~N}_{13} \mathrm{O}_{6}, M_{\mathrm{r}}=419.14, T=90(2) \mathrm{K}$, hexagonal, space group $P 6_{3} / m, a=b=12.2263(6), c=6.8854(6) \AA, V=891.35(10) \AA^{3}$, $Z=2, \rho_{\text {calcd }}=1.562 \mathrm{Mgm}^{-3}, \mu\left(\mathrm{Mo} \mathrm{K}_{\alpha}\right)=0.127 \mathrm{~mm}^{-1}, F(000)=428,2 \theta_{\max }=$ $60.0^{\circ}, 9260$ collected reflections, 937 unique reflections $\left(R_{\text {in }}=0.0485\right), 68$ parameters, $S=1.139, R_{1}=0.0372(I>2 \sigma(I)), w R_{2}$ (all data) $=0.1099$, max. $/ \mathrm{min}$. residual electron density $+0.447 /-0.275 \mathrm{e}^{-3}$. Crystallographic data (excluding structure factors) for the structure reported in this paper have been deposited with the Cambridge Crystallographic Centre as supplementary publication no. 738374. Copies of the data can be obtained free of charge on application to CCDC, 12 Union Road, Cambridge CB2 1EZ, UK. [Fax: (internat.) +44-1223/336-033; E-mail: deposit@ccdc.cam.ac.uk).

\section{Spectroscopic and thermal characterisation}

NMR spectrua were recorded on a BRUKER DPX 400 instrument at room temperature in $\mathrm{D}_{2} \mathrm{O}$ solution. The chemical shifts are reported relative to TMS. ${ }^{13} \mathrm{C}$ CP/MAS NMR spectra were measured with a conventional impulse spectrometer DSX Avance 400, Bruker.
FTIR spectra were recorded in a range from 400 to $4000 \mathrm{~cm}^{-1}$ at room temperature using a Nicolet 510-FTIR spectrometer. The Raman spectra were obtained using a Bruker RFS 100/S, Neodym YAG Laser instrument.

The thermogravimetry measurement was performed using TG/DTA (Seiko Instruments) with a heating rate of $5 \mathrm{~K} / \mathrm{min}$, argon flowing rate of 300 $\mathrm{ml} / \mathrm{min}$, maximum temperature $800{ }^{\circ} \mathrm{C}$. Elemental analysis was performed on a Heraeus $\mathrm{CHN}$ rapid analyzer.

\section{Acknowledgement}

We gratefully acknowledge the German Research Foundation (DFG project-\# KR 1739/9-2) for financial support. Dr. E. Brendler is acknowledged for performing the solid state NMR measurements.

\section{References}

[1] For current literature see for example: a) A. Thomas, F. Goettmann, M. Antonietti, Chem. Mater. 2008, 20, 738-755; b) S. Tragl, K. Gibson, J. Glaser, G. Heydenrych, G. Frenking, V. Duppel, A. Simon, H.-J. Meyer, Z. Anorg. Allg. Chem. 2008, 634, 2754-2760; c) F. Tian, J. Wang, Z. He, Y. Ma, L. Wang, T. Cui, C. Chen, B. Liu, G. Zou, Phys. Rev., 2008, B78, 235431-2354316; d) X. Li, J. Zhang, L. Shen, Y. Ma, W. Lei, Q. Cui, G., Zou Appl. Phys. A 2009, 94, 387-392; e) K. Maeda, X. Wang, Y. Nishihara, D. Lu, M. Antonietti, K. Domen, J. Phys. Chem. C 2009, 113, 4940-4947; f) A. Majumdar, G. Scholz, R. Hippler, Surf. Coat. Technol. 2009, 203, 2013-2016; g) M. Döblinger, B. V. Lotsch, J. Wack, J. Thun, J. Senker, W. Schnick, Chem. Commun., 2009, 1541-1543.; for reviews see: h) E. Kroke, M. Schwarz, Coord. Chem. Rev., 2004, 248, 493-532; i) G. Goglio, D. Foy, G. Demazeau, Mater. Sci. Eng. R, 2008, 58, 195227.

[2] E. Kroke, M. Schwarz, E. Horvath-Bordan, P. Kroll, B. Noll, A. D. Norman, New J. Chem. 2002, 26, 508-512.

[3] L. Gmelin, Ann. Pharm. 1835, 15, 252-264.

[4] J. Liebig, Ann. Chem. Pharm. 1844, 50, 337-361.

[5] L. Pauling, J. H. Sturdivant, Proc. Nati. Acad. Sci. 1937, 23, 615-620.

[6] E. Horvath-Bordon, E. Kroke, I. Svoboda, H. Fuess, R. Riedel, New J. Chem. 2005, 29, 693-699.

[7] a) F. Goettmann, A. Fischer, M. Antonietti A. Thomas, Angew. Chem. Int. Ed. 2006, 45, 4467. b) A. Thomas, A. Fischer, F. Goettmann, M. Antonietti, J.-O. Muller, R. Schlogl, J. M. Carlsson, J. Mater. Chem. 2008, 18, 4893-4908.

[8] N.E.A. El-Gamel, M. Schwarz, E. Brendler, E. Kroke, Chem. Commun. 2006, 4741-4743.

[9] a) B.V. Lotsch, W. Schnick, Chem. Mater. 2006, 18, 1891-1900. b) A. Sattler, L. Seyfarth, J. Senker, W. Schnick, Z. Anorg. Allg. Chem. 2005, $631,2545$.

[10] see e.g. a) E. Kroke, T. Gmeiner, M. Schwarz, WO 2006034784; b) A. König, U. Fehrenbacher, E. Kroke, T. Hirth, J. Fire Sci., 2009, 27, 187211.

[11]X. Wang, K. Maeda, A. Thomas, K. Takanabe, G. Xin, J.M. Carlsson, K. Domen, M. Antonietti, Nature Mater. 2009, 8, 76-80.

[12] S.J. Makowski, D. Gunzelmann, J. Senker, W. Schnick, Z. Anorg. Allg. Chem. in press.

[13] S.J. Makowski, W. Schnick, Z. Anorg. Allg. Chem. in press.

[14] a) J. Wagler, N.E.A. El-Gamel, E. Kroke, Z. Naturforsch. 2006, 61b, 975-978; b) M.R. Schwarz, H. Ehrenberg, M.A. Kloc, E. Kroke, Heterocyles 2006, 68, 2499-2507; c) N.E.A. El-Gamel, L. Seyfarth, J. Wagler, H. Ehrenberg, M. Schwarz, J. Senker, E. Kroke, Chem. Eur. J. 2007, 13, 1158-1173; d) N.E.A. El-Gamel, J. Wagler, E. Kroke, J. Mol. Struct., 2008, 888, 204-213.

[15]D.R. Miller, D.C. Swenson, E.G. Gillan, J. Am. Chem. Soc. 2004, 126, 5372-5373.

[16]E. Bordon, E. Kroke, I. Svoboda, H. Fueß, R. Riedel, N. Sharma, A.K. Cheetham, Dalton Trans. 2004, 3900-3908. 


\section{Page 5 of 6}

1

2 [17]G. M. Sheldrick, SHELXS-97, Program for the Solution of Crystal 3 Structures, Universität Göttingen 1997.

4

5

6

7

8

9

10

11

12

13

14

15

16

17

18

19

20

21

22

23

24

25

26

27

28

29

30

31

32

33

34

35

36

37

38

39

40

41

42

43

44

45

46

47

48

49

50

51

52

53

54

55

56

57

58

59

[18]G. M. Sheldrick, SHELXL-97, Program for the Refinement of Crystal Structures, Universität Göttingen 1997. 
